\title{
A ARTE BRASILEIRA NÃO SE RESUME AO EIXO RIO DE JANEIRO - SÃO PAULO: SOTAQUES POÉTICOS DO NORDESTE POR UMA URGENTE HISTÓRIA DA ARTE
}

Brazilian art is not limited to the axis Rio de Janeiro - São Paulo: poetic accents from the Northeast for an urgent history of art

El arte brasileño no se limita al eje Río de Janeiro - São Paulo: acentos poéticos del Nordeste para una historia urgente del arte

Eduardo Bruno [Universidade Federal do Pará, UFPA] ${ }^{*}$

João Paulo Lima [Universidade Federal do Ceará, UFC] * *

Waldírio Castro [Universidade Estadual do Ceará, UECE] ***

BRUNO, Eduardo; LIMA, João Paulo; CASTRO, Waldírio. Revista Poiésis, Niterói, v. 23 , n. 39 , p. 55-72, jan./jun. 2022. [DOl: https://doi. org/10.22409/poiesis.v23i39.52943]

Este documento é distribuído nos termos da licença Creative Commons Atribuição Não Comercial 4.0 Internacional (CC-BYNC) (c) 2022 Eduardo Bruno, João Paulo Lima, Waldírio Castro.
RESUMO Esse texto, a partir da apropriação do termo sotaque do campo da linguística, aposta na dimensão plural da produção artística contemporânea do/no nordeste brasileiro, com o objetivo de estabelecer rupturas na/com a história da arte nacional, tradicionalmente narrada a partir do eixo Rio de Janeiro/São Paulo. Para tal, divido em três tópicos, que podem ser lidos na ordem que se preferir, o texto costura reflexões acerca do lugar do nordeste no sistema de arte nacional, com debates históricos, poéticos, estéticos, políticos e sociais que se estabelecem entre as regiões nordeste e sudeste. Sendo assim, cada parte do texto, mobiliza um escopo de referências teóricas e artísticas, provocando a ideia de sotaques poéticos para demarcar territórios propositivos para a formulação de muitos (outros) mapas (im) possíveis da arte brasileira.

PALAVRAS-CHAVE Sotaque poético; arte brasileira; nordeste brasileiro.

RESUMEN Este texto se centra en la dimensión plural de la producción artística contemporánea del nordeste brasileño, a partir de la apropiación del término "acento" del campo de la lingüística. Busca establecer rupturas en/con la historia del arte nacional, tradicionalmente narrada por Río de Janeiro/São

* Eduardo Bruno é doutorando em Artes na UFPA com bolsa FAPESPA. E-mail: eduardobfreitas@hotmail.com

* * João Paulo Lima é artista-performer-educador, escritor e Mestre em Literatura Comparada pela UFC. E-mail: castro.waldirio@gmail.com *** Waldírio Castro é artista transdisciplinar, arte educador, curador, produtor e mestrando em Artes da UFC. E-mail: jp.movimentos@gmail.com

Revista Poiésis, Niterói, v. 23, n. 39, p. 55-72, jan./jun. 2022. [DOl: https://doi.org/10.22409/poiesis.v23i39.52943] 
Paulo. Dividido en tres temas que pueden leerse en el orden que se prefiera, hilvana las reflexiones sobre el lugar del noreste en el sistema artístico nacional, con los debates históricos, poéticos, estéticos, políticos y sociales que se establecen entre las regiones del noreste y del sureste. Además, cada parte del texto moviliza un ámbito de referencias teóricas y artísticas y provoca la idea de acentos poéticos para demarcar territorios propositivos para la formulación de muchos otros (im)posibles mapas del arte brasileño.

PALABRAS CLAVE Acento Poético, Arte brasileña Nordeste brasileño

ABSTRACT This text bets on the plural dimension of contemporary artistic production from/in the Brazilian northeast, based on the appropriation of the term "accent" from the field of linguistics. It aims to establish ruptures in the history of national art, traditionally narrated by Rio de Janeiro/São Paulo. Thus, it is divided into three topics that can be read in any order one prefers, and it sews reflections about the place of the Northeast in the national art system, with historical, poetic, aesthetic, political and social debates that are established between the Northeast and the Southeast regions. Moreover, each part of the text mobilizes a scope of theoretical and artistic references, provoking the idea of poetic accents to demarcate propositional territories for the formulation of many (other) (im)possible maps of Brazilian art.

KEYWORDS Poetic accent; Brazilian art; Brazilian northeastern 
Esse texto é um labirinto. Uma armadilha armada não para responder às históricas falácias da história da arte no Brasil. Como bom labirinto, não pretendemos apresentar respostas, pois não há. Qualquer tentativa de resposta seria mais uma outra falácia, uma caricatura, um reducionismo criado e construído para aprisionar nossas diversas identidades. Nesse sentido, propomos que visualizemos o mapa do Brasil por outra cartografia, relocalizando as proximidades e lonjuras que constituíram essas gentes. Contudo, sempre partindo do plural como referência, dos diversos sotaques, seja com o /s/vozeado ou não.

Sendo assim, esse texto aposta na dimensão do sotaque, numa apropriação conceitual de um termo da linguística que é usado para designar os modos como cada falante de uma língua faz uso dela ao seu modo e ao modo de pequenos grupos que se inserem no contínuo de uma população. Sotaques poéticos do Nordeste. Sim, nós temos sotaques, e vocês, não têm?

\section{É por esses sotaques que nos comparam e/ou} desamparam, que decidimos alinhavar nossos textos no risco de encontrar e/ou desencontrar nossas escritas. É pela compreensão das diversas poéticas que apontamos nosso olhar acerca dos nossos sotaques, demarcando territórios possiveis e propositivos no intuito de provocarmos muitos [outros] mapas [im]possíveis.

\section{SOTAQUE 1 - DAS POÉTICAS PERFORMATIVAS}

Que historicamente o povo nordestino, devido a diversas questões, entre elas o empobrecimento estratégico da região em decorrência do escoamento das riquezas para região do sudeste, foi forçado a migrar principalmente para São Paulo e Rio de Janeiro, já é de conhecimento de todos. Uma simples tarde assistindo a televisão brasileira, principalmente no fim de semana, podemos ver como a pobreza nordestina vem sendo espetacularizada e rentabilizada. De Gugu Liberato a Luciano Huck, o nordestino, seja na tentativa de voltar para sua terra ou na necessidade de ter uma moradia digna, vem sendo apresentado e construído pela mídia hegemônica como o pobre, uma vítima da seca que migra para o sudeste na busca do sucesso, ou seja, toda uma formulação do que a escritora Chimamanda Ngozi Adichie nomeia enquanto história única [2019] criada para designar um povo.

As riquezas do país, principalmente com a chegada da Corte portuguesa no Brasil, vêm sendo escoadas para a região sudeste há bastante tempo, ou seja, o pobre que hoje diverte as tardes de domingo vem sendo forjado por meio de uma desigualdade social historicamente construída. Desigualdade essa que não apenas constrói/ construiu o processo de migração do nordestino para o Sudeste, mas também fetichiza, planifica 
e formula estereótipos, "e o problema com os estereótipos não é que sejam mentira, mas que são incompletos. Eles fazem com que uma história se torne a única história" [ADICHIE, 2019, p. 26].

Esse cenário não seria diferente na perspectiva das artes. Pertinente lembrarmos que, o que é ensinado [desde do fundamental até a universidade] enquanto história da arte brasileira, na maior parte, não passa da história da arte do sudeste brasileiro sendo narrada/tomada como história da arte nacional. Entre Café com Leite, Jardins e Leblon, muito se sabe e se conta sobre as perspectivas da arte sudestina enquanto um sinônimo do que se entende como história da arte no Brasil. Muito se sabe, por exemplo, sobre a Semana de Arte Moderna, de 1922, que ocorreu em São Paulo-SP, mas pouco, ou quase nada se sabe/fala sobre a Padaria Espiritual, de 1892, que ocorreu em Fortaleza-CE.

Contudo, não queremos cair na generalização homogeneizada sobre a formulação da história da arte brasileira apenas em um viés de geolocalização, sabemos que, mesmo nessa formulação da arte brasileira concentrada a partir do sudeste, há toda uma maquinação para se produzir uma identidade artística nacional com base em uma construção branca-cisgênera-heterossexual-capacitista-classista. A contrapelo disto, o pensamento que estamos mobilizando nesse texto aciona fazeres e teorizas [práxis] em arte que relacionam a geolocalização da produção nordestina, mas não com o objetivo de responder ao modelo hegemônico da figura da identidade artista nacional. Nossa provocação para uma outra história da arte brasileira parte de uma outra formulação da história, um outro tempo e um outro espaço. Uma perspectiva diferente da dominante, não como uma contradição a esta, mas uma história que é própria em si.

Quando escolhemos sobre o que falar em uma formulação histórica, definimos quais são as obras relevantes para serem lembradas, ao passo que relegamos todas as outras produções ao esquecimento institucionalizado. A formulação de uma história a ser contada acontece na relação com o poder vigente e os interesses sociais em curso, "é impossível falar sobre história única sem falar sobre poder [...] o poder é a habilidade não a penas de contar a história de outra pessoa, mas de fazer que ela seja sua história definitiva" [ADICHIE, 2019, p. 23]. Com isto, a longa lista da exclusão de artistas nordestinos, principalmente aqueles que não correspondem ao processo da formação de uma ideologia dominante branca-cisgênera-heterossexual-capacitista-classista, se dá também como uma forma de possibilitar a reprodução do poder hegemônico e manter os locais de privilégios no país. 
Nesse sentido, apontamos que na esteira das perspectivas das tecnologias de exclusão e silenciamento, no caso do Brasil, é ingênuo não pensar na relevância da geolocalização como mais uma forma de se maquinar uma identidade nacional que privilegia e aciona lugares de poder a poucos. Ainda temos uma produção de conhecimento institucionalizado, não apenas em arte, muito concentrado no sudeste do país, lá estão as universidades mais antigas e que historicamente possuem o maior investimento, é também nessa região onde se tem a maior concentração de renda, além do poder de influenciar a política nacional. Talvez, por questões como essas, entre outras, é que a geolocalização, como estratégia de formulação de um lugar de privilégio, ainda seja pouco ou quase nunca discutida de forma transversal nos espaços de poder.

Em detrimento de uma concentração de fluxos de mercadoria, pessoas e poder político/econômico, historicamente formulado, a região sudeste, principalmente Rio de Janeiro e São Paulo, foi/é o local que vem conseguindo se desenvolver, de modo mais rápido, aos moldes da modernização ocidental. De um ponto de vista material, se os meios de produção, historicamente, já estavam sendo construídos no sudeste, o escoamento econômico do país já vem ocorrendo há bastante tempo para a região, construindo, assim, uma elite econômica, nada mais natural que as grandes cidades nacionais estejam inseridas na região sudeste do país. Desta forma, em uma corrida desigual, devido a inúmeros processos históricos, criou-se todo um cenário para que os demais moradores do Brasil, principalmente os nordestinos, alimentassem o sonho de conseguir "descer" para tentar o sucesso no sudeste, assim como aponta a composição musical, "Carneiro", de 1974, dos artistas fortalezenses Ednardo e Augusto Pontes:

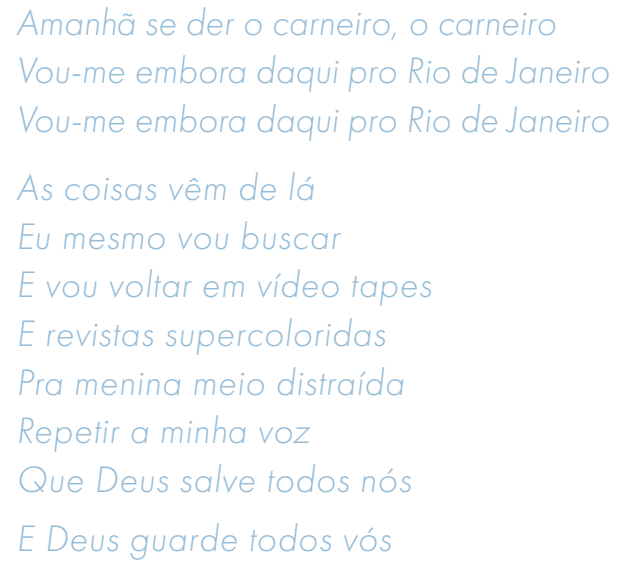

O sonho de ir embora para o Sudeste, nem que seja por meio da sorte de ganhar no jogo do bicho, circula o desejo nordestino quase como um fantasma. A ida ao sudeste, deslocando-se para o eixo de privilégio do país, ainda hoje, paira como uma histórica única de sucesso para o nordestino. Uma experiência de deslocamento que, 
quando "conquistaram", vem junto com o estereótipo e planificação das identidades nordestinas: nordestino em São Paulo é paraíba e no Rio de Janeiro é baiano. Um vício de linguagem histórico, mas que até hoje é usado para designar "esse povo que tem sotaque cantando".

O perigo de percebermos nossas identidades por meio de uma estrutura de poder que condiciona a geolocalização como justificativa para a formulação pasteurizada das identidades a partir do olhar do local de privilégio, é sermos cooptados pela ideia de que é possível envelopar toda uma população e seus fazeres culturais a partir de uma categoria imposta. Entretanto, como estratégia de fabricação de alianças [BUTLER, 2018], podemos articular o fato de sermos lidos como nordestinos para profanar ${ }^{1}$ essa nomeação a partir do reconhecimento do processo histórico que nos subalternizou a uma estrutura de poder e, assim, nos organizarmos para destituir essa estrutura historicamente estabelecida.

Nesse sentido, apostando na dimensão do sotaque como uma forma de fugir da homogeneização historicamente imposta aos nossos corpos e produções artísticas, afirmamos a diferença presente nas poéticas geolocalizadas no nordeste brasileiro. Se nossos sotaques sempre foram usados como forma de sermos apontados como o outro, nos apropria- mos dessa dimensão do sotaque para afirmarmos nossas diversas poéticas, estéticas e políticas. Destacar a produção de artistas locais [nordestinos] que operam ações em arte que deslocam o olhar para poéticas que surgem de outras centralidades de mundo e narrativas, a partir da experiência construída com seus corpos e comunidades, é também perverter a ideia de nordestino sem abandonar a necessidade de apontar o apagamento histórico da produção artística local.

Com isto, entre alguns artistas do cenário contemporâneo nordestino, apontar o trabalho de Maria Macedo, artista cearense que nasceu no distrito de Quitaiús do município de Lavras da Mangabeira-CE, é acessar a poética de uma artista nordestina que opera suas criações ao passo que afirma os seus e seu entorno, desviando da ideia sine qua non de que para produzir arte é necessário se deslocar para os eixos de "privilégio". Dentro da extensa produção de Macedo, destacamos o projeto "Dança para um futuro cego" [2021], trabalho que hibridiza performance, fotografia e vídeo. Nessa obra, o corpo preto de Maria Macedo, vestido em vermelho, juntamente a paisagem do sertão do Ceará e objetos como facão, pote de barro e prato de louça branca, ao passo que mobiliza imagens e performatividades acerca do sertão, rompe com os visíveis pré-estabelecidos para a região. Acessar 
esse trabalho é um exercício urgente de percepção acerca de narrativas outras, de sotaques poéticos que estão em curso rompendo com os possíveis impostos aos corpos nordestinos em suas interseccionalidades [AKOTIRENE, 2019].

"[des]Ordem e re[Pro]gresso", que teve sua primeira execução em 2018 na primeira edição do Festival de Performance do Ceará: Imaginários Urbanos². Em uma ação que a olhos rápidos pode passar despercebida, Lívio senta-se em um tamborete de plástico, na Praça do

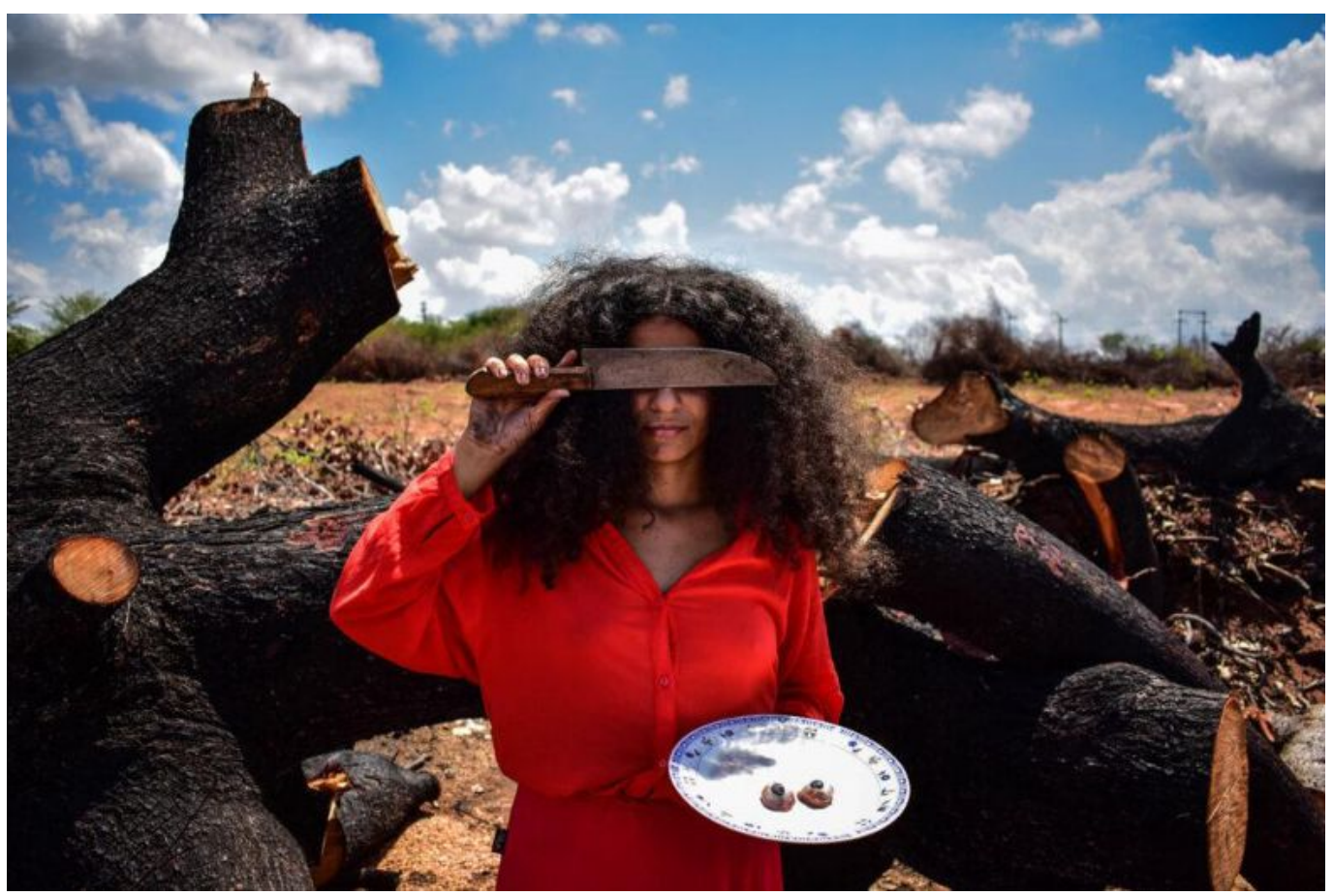
Ferreira, localizada na cidade de Fortaleza/ CE, para, com linhas vermelhas, costurar os retalhos do que antes era uma bandeira brasileira. Ao final, a bandeira é "hasteada" em uma pequena árvore da praça.

Tais sotaques poéticos do nordeste, localizados no Ceará, na região do Cariri, fazem parte desse caleidoscópio da diferença que ressoa com tantas outras produções artísticas nordestinas. Cada um, longe de uma harmonia, produz em arte suas questões e mobiliza os materiais e os suportes que Ihes parecem necessários. Com isto, olhar para estas e tantas outras obras produzidas por artistas do nordeste é um exercício de ruptura

Revista Poiésis, Niterói, v. 23, n. 39, p. 55-72, jan./jun. 2022. [DOl: https://doi.org/10.22409/poiesis.v23i39.52943] 
gente feia, mais escura e morta de fome. Ainda há essa imagem de nós de como os lá de cima? Ironia. Foda-se. Nossos/tSi/e /Ti/ se misturam e reverberamos em narrativas nossas histórias semelhantes de experiências de xenofobia e regionalismos.

Do lado de cá, de cima, tudo tem sido mais pobre. Não há mais tantos auxílios sociais. Abismos, muitos, mais gente na rua e mais miseráveis da seca e da cerca, ambas historicamente sustentadas pela decisão de um tal imperador que se traslada da Bahia para "construir" a sede do reino brasiluso. A lusofonia débil na terrabrasilis se instaura na cidade do Rio de Janeiro e o Nordeste começa a perceber o arame farpado que ratificará nosso lugar de exclusão. Pra sempre? Depois de Minas há a Bahia, depois tudo é Nordeste. Ouvia isso desde menino de parentes que foram morar pelo Sul. Até os apelidos dados generalizam a espécie brasileira xingada: ei, paraíba! Sai da frente, bahiano! E por aí foi e vai nossos ecos de um Brasil "cordialmente" excludente [HOLANDA, 1998] que retroalimenta a superioridade sul-sudeste $X$ norte-nordeste.

De repente, deparo-me com o texto de um conterrâneo cearense, Thiago Florêncio, intitulado propositalmente "Nativo ausente". Na sua escrita, cita-se as "feridas sutis" lembradas por Nietzsche e menciona a mexicana Gloria Anzaldua, para quem a fronteira EUA/MÉXICO é uma ferida aberta em que o primeiro mundo atrita o terceiro e sangra.

Decido olhar o mapa do Brasil pelo google maps e imagino a ferida no meu mapa individual e periférico.

Onde começa a ferida do Brasil que vibra uma dor? Por onde começar a sutura? De onde e quando a gente resolve se boicotar e criar uma ferida entre norte e sul e mapearmos quem é mais ou menos gente, mais ou menos brasileiro, mais ou menos nativo, de fala melhor ou pior? Quem começou a dizer que o outro é que fala errado, que o sotaque do outro é que é feio, estranho, bizarro, engraçado ou dissimuladamente: bonitinho!

Estamos por aqui no Norte espalhando alegria e tristeza, excesso de recursos e escassez de investimentos. Aos olhos de boa parte da população sudestina ainda somos sustentados pelo povo que trabalha, sabemos apenas fazer festa e ter filhos. Que somos preguiçosos e burros da cabeça chata. Parece mentira, mas as frases são ainda motivo de chacota e zoeira, sim. E por que não espontaneidades sincera quando viramos motivos de piada na TV, no cinema ou nos turismos Brasil afora.

Nossos sotaques têm se misturado mais, conversado e criado um território afim, a fim de suturar as feridas entre o que a geopolítica de homens cis brancos criou. Os sotaques são fronteiras líqui- 
das que nem cercas, rios, serrotes, pontes, muros conseguem desgrudar. Nossa fonética vai se resvalando e criando outros modos e pontos de articulação, amalgamam nossos sons de ancestralidades, os sons que sobram do sangue derramado pelo europeu que pensou ter vencido o que não é matado. Sotaque é corpo, é subjetividade, é identidade. Os sons aspirados, fricativos, sibilantes, oclusivos, todos de norte a sul desse país não foram ganhos de acentos europeus, mas de uma cor mais escura, ninado no colo das mulheres indígenas e nas tetas das mães pretas. Herdamos, cantamos e dançamos o que é cafuso-caboclo, mameluco, afro,indígena e liquidamos com to da a tentativa de cerceamento que ainda nos impõem uma regra da gramática do português padrão. Ou patrão?

Se andarmos pelos territórios das artes nossas supostas fronteiras se liquidificaram ainda mais. Nossas trocas e percepções de si tem ido pra frente sem deixar de olhar pra trás na tentativa de não vacilar mais para a construção de uma história mais presente, mais possuída, desfeita de autorizações de outrem. Criamos nossas pontes mais largas e túneis profundos para fugir, desviar do que o eixo sul parecia por décadas vociferar como únicas verdades estéticas.

O exemplo disso sempre foi a literatura cearense, desde o século 19, quando tudo já havia sido trasla- dado para o eixo mais sudestino, autores e autoras foram se constituindo escritores de grande relevância para a criação literária nacional. Não fosse autores cearenses, a literatura realista-naturalista se ressentiria de personagens-tipos para compor o quadro de nossas influências deterministas bem casadas com a miséria dos retirantes e das paisagens ásperas do sertão do Ceará.

Mas não ficamos por aí. A literatura contemporânea cearense [aqui cito o Ceará por ser meu estado natal] se envereda por uma escrita experimental, disruptiva e desconcertante. Escritoras mulheres se destacam, escritores negros periféricos, espaços da linguagem da escrita que sempre ousaram mesmo se tratando da província do Siará-Grande.

Autoras como Sara Síntique, Nina Rise, Nádia Fabrici, Argentina Castro, Vitória Régia, Anna K Lima e Mika Andrade se reúnem e catalogam contos eróticos de jovens autoras cearenses e ampliam com "O Olho de Lilith" a literatura com seu olhar sempre predecessor. Numa país-região-estado-cidade, onde o machismo ainda prepondera e nos remete à mulher que precisa recorrer à figura do macho para ser vista mais forte, jovens escritoras extrapolam o purismo acadêmico e poetizam suas "escrevivências" para reescrever a la Conceição Evaristo modos de gritar "isso aqui também é nosso" e rompem no cenário litero-brasileiro suas provocações porosas. 
Não diferente, autores como Talles Azigon também "lançam mão" de suas composições e escolhem capturar olhares sobre cidade, periferia, corpo gay, corpo negro, homoafetividades e denúncia para construir uma trilogia literária de poesias periféricas publicadas como o nome de "Sarau" e lançada, recentemente, pela editora Substância [Fortaleza-CE]. Mesma editora por onde publiquei meu recente livro "Viço, Manco, Voo", que enquanto um escritor def-gay-nordestino-negro se vê nesse des-cânone, em que a dissidência e lírica periférica desbrava outras extensões possíveis para o campo literário.

Tudo isso acontece porque há uma necessidade cada vez mais incitante de nos conectarmos, "mas conectar é verbo transitivo direto que, de forma bem mais ampla, representa a agregação de diversos elementos em busca de objetivos comuns. Reconectar, neste sentido, é refazer conexões que foram perdidas." [RUFINO, 2020]. Refazer o que está perdido pela colonização e recolonização, pelo afastamento, pela permanência das desoportunidades, pela divisão ilegal e injusta de riquezas, pelo olhar que empobrece mais que enleva os que estão - contraditoriamente- na parte de cima do mapa. E não só reconectar o Nordeste em si, mas o país que precisa se reformular, removimentar e mover os lugares horizontalmente para nos vermos e enxergarmos melhor [es].

\section{SOTAQUE 3 - DAS POÉTICAS QUEERS}

Uma das estratégias utilizadas para fabricar a ideia de centralidade da região sudeste na mídia hegemônica é a ficção de neutralizar o sotaque. Com isso, ao se impor no centro, tudo que está na margem se estabelecerá como o diferente, o outro, o que não ocupa o centro. Ou seja, para estabelecer uma norma, e aqui, no caso, estamos apontando a fonética, é necessário tomar como referência do que se é ficcionalizado como normal, e, a partir desta referência, compreender/nomear o que não é normal/natural como o diferente, estranho, o outro, o anormal, como aponta Foucault [2014]. Desta forma, seja no jornalismo, na rádio ou nas novelas, criou-se a ficção de um sotaque neutro [que, na verdade, é paulista ou carioca] que deveria ser utilizado na mídia de forma a unificar/normalizar uma fonética na comunicação.

Tal construção de um sistema de representação ${ }^{3}$ [HALL, 2013], não apenas relacionada ao sotaque, mas também a diversos outros estereótipos, reforçados sobretudo na mídia hegemônica e na indústria cultural ${ }^{4}$ ao longo da história ${ }^{5}$, vêm impondo opacidade e discursos simplistas/preconceituosos em relação ao Nordeste. Assim, junto ao processo de uma suposta normalização da fonética a ser utilizada nacionalmente, diversos processos colonizadores de uma elite econômica, geográfica e cultural 
insistem em impor uma centralidade/protagonismo na construção de uma identidade nacional. Acerca de tais processos, parece pertinente apontarmos uma reflexão trazida pela autora Berenice Bento que afirma: "Se trocarmos a palavra "Nordeste" por "Brasil", teremos uma citação do que os europeus pensavam das culturas colonizadas que foram destruídas por eles." [BENTO, 2017, p. 176].

Desta forma, ao falarmos em sotaque, capturamos nesta escrita tal conceito para pensarmos a diferença. Vale destacar que o uso do conceito de diferença se distancia bastante do discurso neoliberal da diversidade, que torna genérico o complexo emaranhado que constitui a diferença. Para Miskolci [2020], o termo diversidade "é uma concepção de cultura muito fraca, na qual se pensa: há pessoas que destoam da média e devemos tolerá-las, mas cada um se mantém no seu quadrado e a cultura dominante permanece intocada por esse Outro" [p.51]. O autor acrescenta que a ideia de diversidade tenta manter intocada a cultura dominante sendo apenas tolerante com a diferença. É assim que os discursos da diversidade vão ganhando as propagandas e os programas de televisão, arquitetando a manutenção daqueles que se colocam no centro das narrativas hegemônicas. Viver, se relacionar e compreender o mundo com/pela diferença estabelece que o outro, o diferente, o que não está no cen- tro, nos atravesse, nos transforme e nos empreste suas lentes para enxergar o mundo de forma compartilhada compreendendo as diferenças de cada um/uma/ume. Ademais, no Nordeste, diferente do que a mídia hegemônica afirma, temos diferentes sotaques. Quem mora em Natal tem a fonética diferente de quem mora em Fortaleza, que tem a fonética diferente de quem mora em João Pessoa, assim por diante. Além da fonética, a construção social-política-colonizatória, mesmo que atravessada por sistemas de representação em comum, tem peculiaridades.

Dando continuidade às nossas reflexões, podemos destacar que, desviando ou construindo simbólicos outros, a diferença presente no Nordeste, que estamos chamando aqui de sotaque, está presente em diversas produções artísticas. Tais produções vêm rompendo pressupostos hegemônicos e reinventando o imaginário dos/das/des sujeitos/as/es nordestinos/as/es. Sobretudo nas poéticas dissidentes de gênero, sexualidade e corporeidade, que pela lente dos estudos queer ${ }^{6}$ podemos chamá-las de produções queer/transviadas, tais produções vêm reimaginando o Nordeste. Questões comumente direcionadas aos sujeitos nordestinos como a heterocentralidade, o machismo, o patriarcalismo e a religiosidade vêm sendo questionadas e reelaboradas por tais produções desviantes. 
Com isso, por meio da invenção de poéticas artísticas enquanto homem gay, artista-pesquisador, nordestino, nascido na cidade de Campina Grande - PB, nos últimos anos venho sendo atravessado pelas diversas reimaginações [MOMBAÇA, 2016] propostas por artistas contemporâneos da Paraíba. Neste recorte, destaco a produção de artistes paraibanes como Julian Santos ${ }^{7}$, Bixarte ${ }^{8}$, Val Donato ${ }^{9}$, a coletiva paraibana EKÈ Candomblé System ${ }^{10}$ que recentemente constitui a Ekè audiovisual, André da Costa Pinto ${ }^{11}$, entre tantes outres artistes desviantes. Artistes/artivistes com sotaques paraibanos que reafirmam a diferença e vêm tensionando o status quo hegemônico da hetero-cis-centralidade.

A partir disto, a arte parece nos mostrar um caminho para reinventar outras relações/agenciamentos exercitando inclusive a criação de outros mundos/simbólicos/ sistemas de representação. Unindo arte e ativismo

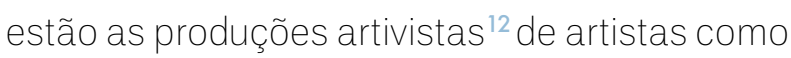
Julian Santos, multiartista paraibano, homem-trans que reimagina e inventa com seu sotaque paraibano prosódias por meio da música, questionando, denunciando e tensionando a cisnormatividade. Em suas músicas e poemas Julian desabafa e compartilha os embates que o corpo transmasculino sofre no cotidiano, como por exemplo na música "Sua mente sem preparo", onde ele questiona se é o corpo trans que está errado ou se é a mente imersa pela lente cisnormativa que está equivocada.
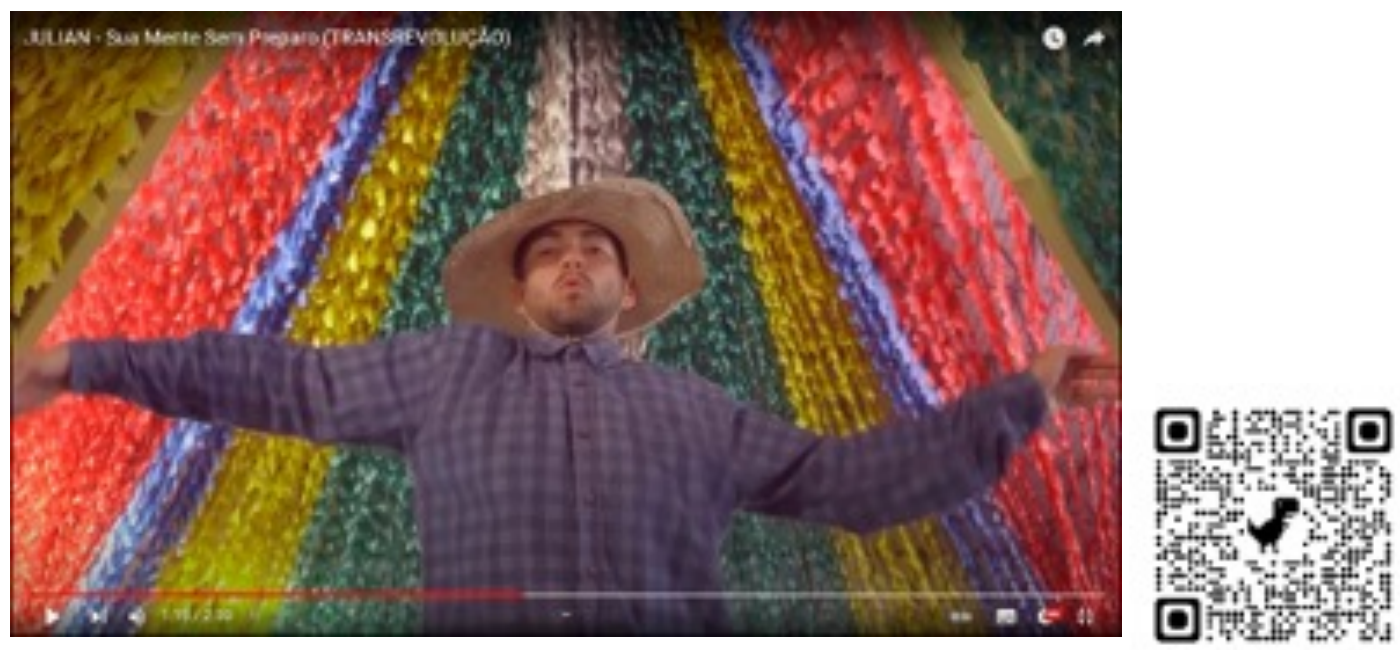

Imagem: Julian Santos em "Sua mente sem preparado" / Qr-Code

Em outro de seus trabalhos, Julian questiona acerca da sociedade falocentrada, que não compreende a existência de homens com vagina e que usam o termo "buceta" como xingamento para designar

Revista Poiésis, Niterói, v. 23, n. 39, p. 55-72, jan./jun. 2022. [DOl: https://doi.org/10.22409/poiesis.v23i39.52943] 
algum acontecimento ruim. No vídeo intitulado "Buceta"14, Julian tensiona o esperado hegemonicamente para o corpo masculino e, por meio do som de sua fala, usa seu sotaque/diferença para falar acerca do sexismo, do machismo, do falocentrismo e a ciscentralidade.

Retomando os atravessamentos acerca dos sotaques nordestinos, gostaria de compartilhar uma experiência que me provocou a construir a poética desta escrita. Ao morar na capital paulistana, entre 2013 e 2017, em busca de supostas oportunidades de trabalho como ator, fui fortemente atravessado pela ficção da centralidade sudestina. "Você não parece nordestino", "Ai que sotaque gostoso, fala de novo", "Nossa, não sabia que existia isso no nordeste", "Tenho um amigo que mora em Recife, Fulano, você conhece?". Essas são algumas das frases que escutei no período em que morei em São Paulo e me provocaram diversos questionamentos sobre o que vem sendo ou o que pode ser o Nordeste ou o/a/e nordestino/a/e.

com o tempo, tal processo violento de neutralidade/naturalização foi imposto sobre meu corpo/ fala. Escutando o que na época era considerado elogio pelos professores de fonoaudiologia: "Nossa!, quase não consigo perceber seu sotaque". Assim como o sotaque, meu processo de desidentificação com o Nordeste e o afastamen- to geográfico, foi tomando meu corpo/fala. Me tornei um personagem de mim mesmo, reforçado positivamente todos os dias pelos amigos e indústria cultural. Um paraibano fantasiado de paulista, perdido nos meus processos de busca por uma identidade.

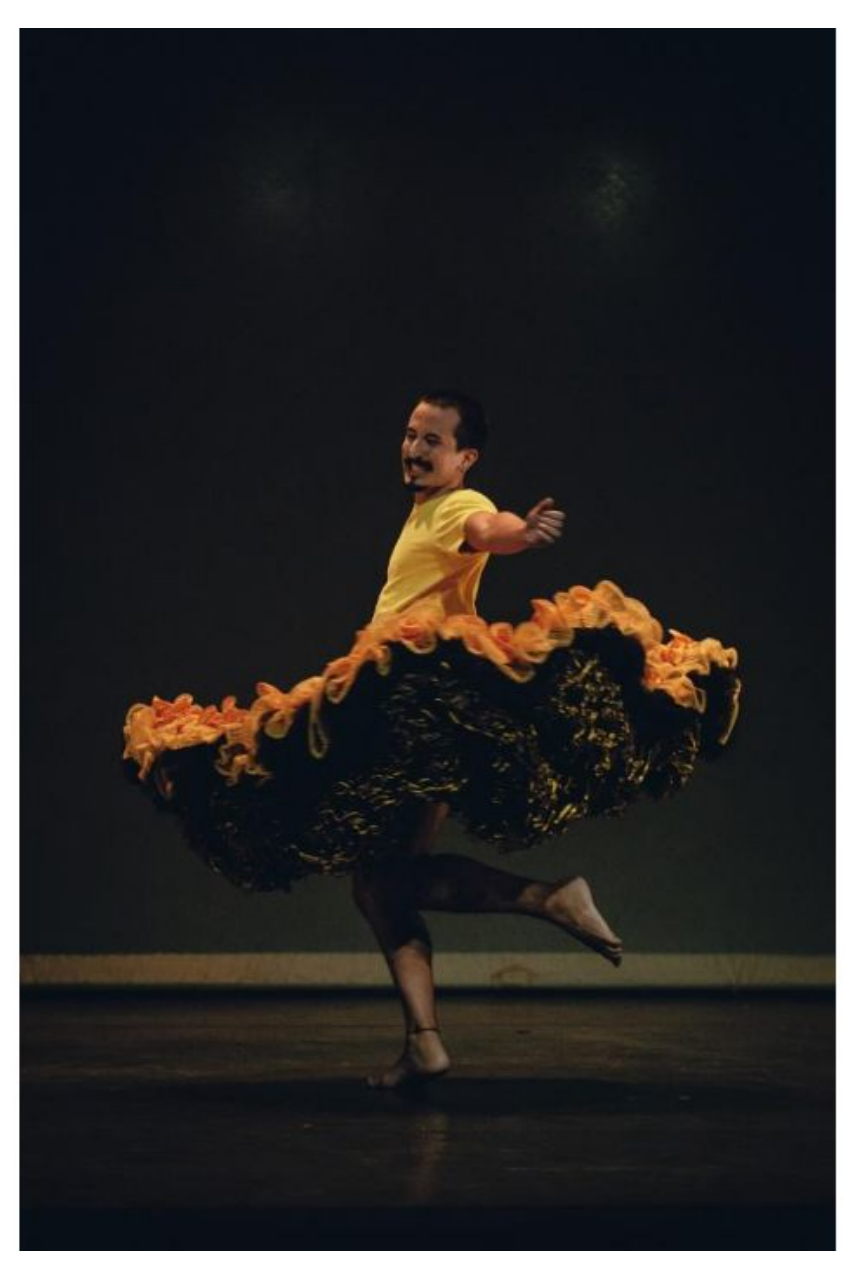

Imagem: Alan Souza BRUNO, Eduardo; LIMA, João Paulo; CASTRO, Waldírio. A arte brasileira não se resume ao eixo Rio de Janeiro-São Paulo: sotaques poéticos.. 
Ao retornar para o Nordeste no final de 2017, agora na cidade de Fortaleza - CE, com uma realidade bem diferente da cidade de Campina Grande - PB, inclusive no sotaque, fui resgatando as alianças e os comuns do que eu compreendia enquanto Nordeste. Neste processo de reencontro retomo as memórias de minha cidade inventando uma pesquisa cênica chamada Rainha do Milho. Na experimentação cênica, áudios de crianças entrevistadas respondem à pergunta "Você já viu um menino usando vestido?". A partir deste questionamento e das memórias da/na infância, em que eu tinha o desejo de vestir e brincar com os trajes da Rainha do Milho, exercito questionar os binarismos que generificam até mesmo a indumentária.

\section{Enquanto artista-pesquisador, venho criando} diversos trabalhos artísticos e pesquisas acerca de como a lente de mundo hetero-cis-normativa vem ficcionalizando uma centralidade hegemônica. Apesar de nos últimos anos o sistema de arte vir capturando diversos lugares de invisibilização histórica como o ser nordestino, negro, periférico, LGBTQIA+, Def, entre outros, não estamos reduzidos ao que o centro nos categoriza. Ademais, enquanto artistes, nordestines atravessades pelas poéticas contemporâneas de dissidência, não inventamos obras de arte apenas com o objetivo de enfrentamento a qualquer ótica de mundo que se coloque no centro. Mais do que enfrentivos, estamos sendo propositivos, não apenas quando inventamos poéticas, mas também quando reimaginamos nossas práticas históricas e o papel, sobretudo, regional, que nos colocaram historicamente. Neste contexto, compreendendo as interseccionalidades [AKOTIRENE, 2019] geográficas, de gênero, sexualidade, raça, classe, corporalidade, e os sotaques/diferenças de cada localidade, podemos apontar que diversos artistes vêm exercitando em aliança, reelaborar, inventar/alargar o que vem sendo entendido como Nordeste.

NOTAS

1 A profanação implica, por sua vez, uma neutralização daquilo que profana. Depois de ter sido profanado, o que estava indisponível e separado perde a sua aura e acaba restituído ao uso [AGAMBEN, 2007, p. 68]. Então profanar é "desativar os dispositivos do poder e devolver ao uso comum os espaços que ele havia confiscado" [AGAMBEN, 2007, p.68].

2 O Festival Imaginários Urbanos é um festival de performance urbana que vem sendo realizado no estado do Ceará desde 2018. Em suas três últimas edições [2018,2020,2021], com curadoria de Eduardo Bruno, o festival é dividido em 3 eixos: 
processos formativos, mostra artística e publicação bibliográfica. Para mais informações, acessa o Instagram: https://www. instagram.com/imaginarios_arte/.

3 "representação é uma parte essencial do processo pelo qual os significados são produzidos e compartilhados entre os membros de uma cultura. Representar envolve o uso da linguagem, de signos e imagens que significam ou representam objetos" [p.32].

4 Como sugestão para uma discussão mais aprofundada acerca do conceito de indústria cultural, sugiro a leitura do artigo de LACOMBE [2019]. O Conceito de Indústria Cultural: Leituras na Contemporaneidade. Disponível em: http://entremeios.com. puc-rio.br/media/11\%20Lacombe\%2Oind.pdf

5 Como sugestão para aprofundamento das questões acerca da historicidade do nordeste, sugiro a leitura dos livros do autor Durval Muniz de Albuquerque Junior "A invenção do Nordeste e outras artes" e "Nordestino: Invenção do "falo" uma história do gênero masculino [1920-1940].

6 Os Estudos Queer, Cuir, Kuir, bixa, transviados, maricas, transmaricas se inventam enquanto agenciamento de diversos autores e pessoas desviantes as normas hegemônicas acerca dos regimes de poder e normatividade sobretudo no que diz respeito as questões de gênero, sexualidade e corporalidade. Compreendo como estudo e não teoria, pois são agenciamentos em constante construção e movimento e com abordagens diferentes, que muitas vezes, não dialogam entre si. Nos últimos anos, os Estudos Queer vêm elaborando, de uma forma mais vertical, acerca das questões de raça, localização geopolítica e classe, como por exemplo; nas proposições dos estudos Queer of color critique. Como primeiro disparador para uma genealogia dos estudos queer, sugiro o artigo "A teoria queer em uma perspectiva brasileira: Escritos para tempos de incertezas" do pesquisador
Arkley Marques Bandeira disponível em: https://periodicos.sbu. unicamp.br/ojs/index.php/rap/article/view/8654815

7 Paraibano, artivista, homem trans, bacharel em arte e mídia pela Universidade Federal de Campina Grande [UFCG], músico, artista e defensor de causas LGBTQ+

8 Poetisa, escritora, atriz e rapper, a artista paraibana Bixarte é uma expoente do Rap Paraibano.

9 Vocalista e compositora, destaque no cenário musical paraibano de forma solo e na banda 'Os Cabeças'.

10 Se intitula em sua página como uma Coletiva Ekè formada por bixas - afras - anarkas - futurísticas, que estão excitadas.

11 Cineasta paraibano idealizador do Comunicurtas - Festival de cinema de Campina Grande - PB. Ao longo de sua trajetória, em suas produções como "Amanda \& Monick", "Tudo que Deus Criou", "O tempo feliz que passou" e "Madame", o cineasta conta histórias reais e ficcionais de sujeitos desviantes de gênero, sexualidade, corporeidade, construindo imaginários outros acerca da Paraíba.

12 Podemos compreender artivismo como um movimento de artistas disruptivos, encontrados principalmente nas estéticas contemporâneas, que exercitam romper com os pressupostos normativos, e buscam materializar outros regimes de representação que estão à margem da norma.

13 Para utilizar o QR Code: 1 - Ter um aparelho celular com câmera. 2- Fazer o download de um aplicativo para leitura de QR Codes 3- Após instalado o aplicativo, basta abri-lo e aproximar a câmera do celular no QR Code, onde terá acesso a um link. 4 -Basta clicar no link pra ver/assistir.

14 Disponível em: https://www.youtube.com/watch? $v=a J$ SAyHiNgQA Acessado em 20 de outubro de 2021. 
ALMEIDA, Diogo; ALMEIDA, Luana. Artistas da Paraíba ressaltam a importância do Dia do Orgulho LGBTQ+. G1 Paraíba. Disponível em: https://g1.globo.com/pb/paraiba/noticia/2020/06/28/artistas-da-paraiba-ressaltam-a-importancia-do-dia-do-orgulho-Igbtq.ghtml Acessado em: 20 de outubro de 2021.

ALBUQUERQUE JUNIOR, Durval Muniz de. A invenção do Nordeste e outras artes. São Paulo: Cortez, 2011

ALBUQUERQUE JUNIOR, Durval Muniz de. Nordestino: Invenção do "falo" uma história do gênero masculino [1920-1940]. São Paulo. Intermeios, 2013.

AKOTIRENE, Carla. Interseccionalidade. São Paulo: Pólem, 2019.

ANDRADE. Mika. O olho de Lilith. Ferina. Fortaleza, 2019.

BANDEIRA, A. M. A teoria Queer em uma perspectiva brasileira: escritos para tempos de incertezas. Revista Arqueologia Pública, Campinas, SP, v. 13, n. 1[22], p. 34-53, 2019. Disponível em: https://periodicos.sbu. unicamp.br/ojs/index.php/rap/article/view/8654815. Acesso em: 21 out. 2021.

BENTO, Berenice.Transviad@s:gênero, sexualidade e direitos humanos. Salvador: EDUFBA, 2017.

BUTLER, Judith. Corpos em Aliança e a política das ruas: notas para uma teoria performativa de assembleia. Rio de Janeiro: Civilização brasileira, 2018.

CARULHA, Gabriel. Bixarte: As diversas faces de uma trans não binária dentro do Rap. Brasil de Fato Paraíba, 2019. Disponível em: https://www.brasildefatopb.com.br/2019/11/16/bixarte-as-diversas-faces-de-uma-trans-nao-binaria-dentro-do-rap Acessado em: 21 de outubro de 2021 
FLORENCIO. Thiago. Nativo Ausente. Rio de Janeiro. Imandaia, 2020

FOUCAULT, Michel. História da Sexualidade 1: A vontade de saber. Rio de Janeiro. Paz e Terra. 2014

HALL, Stuart. Cultura e Representação. Rio de Janeiro: Ed. PUC-Rio; Apicuri,2016.

HOLANDA. Sergio Buarque de. Raizes do Brasil. José Olímpio. São Paulo 1998.

LACOMBE, Fabiano. O Conceito de Indústria Cultural: Leituras na Contemporaneidade. Entremeios: Revista Discente do da Pós Graduação em Comunicação Social da PUC -Rio. Edição 15, vol 1, jan-jun/2019. Disponível em: http://entremeios.com.puc-rio.br/media/11\%20Lacombe\%20ind.pdf Acessado em: 20 de outubro de 2021.

MISKOLCI, Richard. Teoria Queer: Um aprendizado pelas diferenças. Belo Horizonte: Autêntica Editora; UFOP, 2020 .

MOMBAÇA, Jota. Rumo a uma redistribuição desobediente de gênero e anticolonial da violência. São Paulo: Fundação Bienal de São Paulo, 2016.

RUFINO. Luis. Encantamento: sobre política de vida. Rio de Janeiro. MV editora, 2020

SUÊNIA ANE. Cantor, compositor e 'artivista', homem trans usa arte como refúgio para conquistar espaço. G1 Paraíba, 2020. Disponível em: https://g1.globo.com/pb/paraiba/noticia/2020/01/31/cantor-compositor-e-artivista-homem-trans-usa-arte-como-refugio-para-conquistar-espaco.ghtml Acessado em 21 de 2021 